\title{
Gender Disrupted During Storytime: Critical Literacy in Early Childhood Education
}

\author{
Cayley Burton
}

Cayley Burton is a master's student in early childhood education at the University of British Columbia. Her research is committed to social justice, anti-oppressive, and inclusive pedagogies within childcare and early learning settings. Email: c.burton@alumni.ubc.ca

In Western early childhood education, cultural expectations about socially acceptable gender performance too often divide young learners along the Victorian sex-gender binary, erasing the beauty of childhood gender children's gender literacy skills through the use of picture books. Building on Judith Butler's theory of recognizability, I argue that gender is a sociocultural construct that can be actively disrupted during storytime activities. Texts featuring gender-nonconforming characters and corresponding pedagogical strategies for deconstructing gender portrayals in children's literature are analyzed and offered in this essay.

Key words: early childhood education; gender nonconformity; gender diversity; picture books; critical literacy diversity. This essay advocates for the development of

\section{Storytime and sociocultural gender norms}

Storytime plays an instrumental role in Western early childhood education (ECE). According to Crisp and Hiller (2011), "a primary means of transmitting cultural values from one generation to the next is through the telling of stories and, in the United States [as in Canada], this commonly comes in the form of children's literature" (p. 197). Storytelling through picture books is used to teach children about social norms and boundaries, including regulations and expectations about gender performance, identity, and expression. Although picture books are diverse in content and representations of reality, influential messages about gender are imparted through the sharing of stories. In this way, gender is a story in and of itself through which children are socialized. Legacies of what I refer to as the Victorian sex-gender binary (VSGB) continue to shape cultural understandings of gender today. A bodily linkage, the VSGB refers to the medicalized and social processes of categorizing children as gendered. Since the Victorian era (1837-1901), binary sex designation at birth (as male or female) carries with it social expectations for binary gender identity (as a boy or girl) expressed in a binary way (masculine or feminine). However, the boundaries of social constructs like the VSGB are limiting for children who do not identify withnor experience their bodies according to-dichotomies of sex or gender. Featuring picture books about gendernonconforming characters during storytime therefore makes ECE more inclusive, and empowering, of gender diversity.

Since, as Katarina Filipović (2018) writes, "traditional stereotypical gender patterns still prevail in children's books used in ... early childhood setting[s]" (p. 319), this essay argues that a critical reading of picture books-referred to here as "disruptive storytime" (Earles, 2017; Yeoman, 1999) —is necessary for the cultivation of gender-affirming ECE learning processes by calling into question hegemonic expectations for children based on their sex-assignedat-birth (SAAB). Through an analysis of three picture books and a discussion of Judith Butler's (2004) theory of recognizability, this essay provides educators with a rationale for the importance of disrupting gender during storytime. By sharing texts such as Jacob's New Dress (Hoffman \& Hoffman, 2014), From the Stars in the Sky to the 
Fish in the Sea (Thom, Ching, \& Li, 2018), and I Am Jazz (Herthel, Jennings, \& McNicholas, 2014) with young learners, the complexity of gender as a culturally situated social construct and performance (Butler, 1990) can be explored in ECE.

Through a literature review, I first explain the connections reiterated in the academic literature between early literacy practices and childhood gender socialization. Following this, I outline my methodology for spotlighting particular picture books in my accompanying analysis. This justification is led by a deconstruction of a two-page spread from each text, examining to what extent picture books for young learners challenge Western discourses of binary gender performance (in which masculinity and femininity are positioned as exclusive from each other vis-à-vis the biological characteristics of children's bodies). The purpose of unpacking snapshots of these texts is to demonstrate the ways in which even excerpts can incite critique about and empowerment of gender during storytime. In this way, gender as a sociocultural construct can be disrupted during storytime, leading to greater support and inclusivity for childhood gender diversity in ECE.

\section{Literature review: Unequal gender representation and picture books}

Gendered scripts (Keenan, 2017) are presented to young readers through picture books and children's literature that mirror North American sociocultural norms. Ya-Lun Tsao (2008) argues, "everything that children read contributes to the formation of self-images that help to construct children's self-identity" (p. 109). Storytime shapes children's developing views of themselves, their peers, and the adults in their lives. As Mattix and Sobolak (2014) explain, "the messages contained in children's books ... have immense importance: the stories told within their pages influence the ways in which children see and react to the world around them" (p. 229). Gender is symbolically represented in picture books depicting the gender performances children observe in daily life. Embedded in the words and images of children's literature are salient messages about the social expectations connected to particular times, places, and identities. As Kristine Gritter and colleagues (2017) explain, "in picture books, gender may be indicated through action, including acts of reading and writing, in both words and illustrations" (p. 571). Through the pedagogical practice of read-alouds (Meller, Richardson, \& Hatch, 2009), picture books are instructional mediums through which the transmission of gender norms occurs. In fact, Crisp and Hiller (2011) write, "by the time children enter kindergarten, they readily differentiate between 'masculine' and 'feminine' roles and have a firm understanding of the types of behavior deemed 'appropriate' for males and females" (p. 197). This classification of roles and behaviour is premised on the VSGB, leaving little room for children's experimentation with gender creativity or fluidity beyond the dualistic positioning of male/female and masculine/feminine. Furthermore, as Mattix and Sobolak insist, "the stories ... shared with young children have a profound impact on how they develop their perspectives and ideas on gender and gender roles" (p. 231). Challenging gender norms through the use of picture books builds awareness about the ways in which identities are socioculturally understood, shaped, and constricted. In order to promote acceptance for childhood gender nonconformity, it is crucial that gender diversity be represented within storytime texts.

Storytime is not a value-neutral activity. Picture books are biased in the ways in which these stories are written, illustrated, and presented in ECE. Although typically authored by adults, picture books are written to appeal to young audiences. Megan Friddle (2017) explains that this genre has particular socializing and instructional power because picture books illustrate "the kinds of identities, identification, and narratives that are possible in adult conceptions of children's lives" (p. 117). Considering the adult-centrism within children's literature, many scholars advocate for a critical reading of texts between adults and children in ECE (Crawley, 2017; Crisp \& Hiller, 2011; Filipović, 2018; Gritter et al., 2017; Kim, 2016; McClung, 2017; Sciurba, 2017). This literacy practice includes discussing those aspects of picture books that resonate, are taken for granted, or neglect children's perspectives by 
asking children to share their perspectives on the texts. A dialogical approach of this kind during storytime allows for children's voices to be better heard and understood (Colliver, 2017) through a teacher-guided conversational exploration of the sociocultural messages and life lessons being communicated through particular stories. A critical reading practice where gender is questioned-rather than essentialized-through text-inspired discussion is necessary because gender norms are internalized early on through children's schooling.

Because, as Mindy Blaise (2005) asserts, gender is often "regulated by the children themselves as they take an active part in the gendering process" (p. 21, original emphasis), it is especially important that gender-based counternarratives are presented to children during early childhood. What problematic reiterations of the gender binary are children relying on to make sense of picture book stories? How do children react to the gender performance and recognizability of certain characters? What if characters are not easily "read" as boys or girls but identify as neither and/or in-between? A critical reading of text also promotes the development of empathy between children and fictional characters who are different from them, a lesson that extends to children's daily interactions with peers regardless of their gender identity and/or expression. Through dialogue stemming from read-alouds, children and teachers in ECE can problematize the VSGB in children's literature.

When gender is understood as, and taught to be, a construct that governs systems of social organization at the same time that it's an important aspect of individual identity development, gender-nonconforming children's experiences are valued and validated as much as their cisgender peers. Using picture books to discuss binary gender norms with young children is important because of the sensitive nature of the early years for gender identity development (Golden \& Jacoby, 2018); perpetuating a binary through ECE pedagogies can limit children's gender expressivity in harmful ways, negatively influencing their sense of self and understanding of others. To foster inclusive, empowering learning environments, Stephen Crawley (2017) writes, "gender-nonconforming children, children who may be questioning their gender identity, and children who have transgender friends and/ or family members must have access to diverse representations of such individuals" (p. 39). Using picture books to initiate conversations about the VSGB - and the ways in which this ideology continues to shape children's gender socialization in Western-dominated societies-leads to meaningful representation in ECE. By thinking critically about the messages and images within picture books, discussions with children about the complexity of gender nonconformity can take place in early learning settings.

\section{Theoretical framework: The (un)recognizable child's gender performance}

According to Butler (2004), "recognition is at once the norm towards which we invariably strive ... and the ideal form that communication takes when it becomes a transformative process" (p. 133). Through the lens of the VSGB, gender performances of masculinity (for boys) and femininity (for girls) are recognized as "a normative ideal" (Butler, 2004, p. 132) in early childhood. This is contingent, of course, on the SAAB of the child(ren) in question. If a female-assigned-at-birth child expresses themselves in a masculine way, they may very well be deemed "unrecognizable" (Butler, 2003, p. 30) to their peers on account of Western, Eurocentric societies' preoccupation with the VSGB. Butler (2004) argues that there are two possible outcomes when a child subject is interpreted as unrecognizable. First, the shift to recognition from a previous lack of recognition involves "a reciprocal process that moves [a self] ... towards an understanding of another self whose difference from [the self] is ethically imperative to mark" (p. 144). Difference is important; it is what makes each child unique in who they are, including their gender, race, sex, (dis)ability, ethnicity, and cultural background. The process that Butler (2004) specifies here is a self-reflection mechanism that can be learned in early childhood, encouraging children to examine their initial reactions to those they encounter who might be expressing gender in ways that defy expectations. While the onus to honour a child for their unique gender identity is indeed a responsibility of the teacher, it is also up to children, 
as young citizens, to extend respectful recognition of all gender identities to all of their peers. The process of recognition between teachers and students of diverse gender identities prioritizes the intellectual and emotional value of saying, I see that this person is different from me, and I also see what we have in common. This is empathy. Or, in Butler's (2004) words: "Recognition implies that we see the Other as separate, but as structured psychically in ways that are shared” (p. 132). Thus, equitable representation of gender diversity can promote positive, supportive, empathetic, and empowering engagement with gendered differences among members of ECE communities.

Picture book characters who do not conform to the gendered expectations associated with their SAAB transgress the boundaries of normative sociocultural performativity within the context of their stories. Narratively speaking, these so-called boundary-crossings often render protagonists unrecognizable to other characters. Because of this, when read aloud during storytime, main characters whose gender expressions challenge the VSGB may even become unrecognizable to adult and child audiences. This is where the second outcome of sociocultural unrecognizability comes into play, causing potential harm. Butler (2004) discusses the ways in which "aggression forms a break in the process of recognition" (p. 134). As I explain later, this response is demonstrated in Jacob's New Dress. One child's hostile response to another on account of being unable to recognize their gender performance communicates the sentiment I see your difference but I refuse to respect it because of how it seems to threaten my understanding of myself. This is a fear-based response to difference. It can be scary when new information, a new person, or a new way of being is introduced to children that conflicts with their current picture of the world and themselves. Through a storytime-based "pedagogy of discomfort" (Boler, 1999), ECE teachers can intervene by teaching children about the validity and diversity of the gender spectrum, eschewing the sociocultural construct of the VSGB. For "if one does not respond to that recognition with aggression," Butler (2004) writes, “... then one is in a position to recognize difference as such and to understand this distinguishing feature of the Other as a relation of 'negation' (not-me) that does not resolve into destruction" (p. 146). Put another way, certain differences between children are not more or less important or valuable; differences between children are important and valuable in and of themselves.

In ECE, Tsao (2008) argues, "the use of picture books that portray non-traditional gender roles ... provides an important contrast to the commonly popular cultural messages often seen and heard by very young children" (p. 113). For characters in books like Jacob's New Dress, who confront normative conceptions of gender and actively resist them, their advocacy, in Crawley's (2017) view, "also alludes to political stances within queer theory that demand change and a reconceptualization of what is accepted as normal" (p. 35). In from the stars in the sky, Miu Lan shares a comparative experience of being "made strange" (Ahmed, 2000, p. 50) at school due to their nonbinary gender expression and identity. Meanwhile, the protagonist of I Am Jazz becomes (un)recognizable to her family and peers through self-advocacy: "I never gave up trying to convince them" (Herthel et al., 2014, p. 14). Each of these picture books contains important messages about gender as a sociocultural construct that shapes the ways in which gender-nonconforming children are perceived by others. By loosening the binary assumption that one's gender identity and expression ought to always conform to one's SAAB, children are given the freedom, safety, and support to be their authentic, creative, multifaceted selves. Through critical reading of the following texts, gender can be effectively disrupted during ECE storytime.

\section{Methods: Selection and analysis of gender-inclusive picture books}

As a queer, cisgender, white-settler Canadian early childhood academic, caregiver, and educator, I bring a particular lens to this picture book selection. I am biased by my subjectivity and privileged social position. Although my methodological criteria for the selection of texts mitigates some of my bias, I still selected and write about three picture books for which I feel a particular appreciation and, based on my experiences of working with young 
children, believe to be pedagogically useful in disrupting gender expectations associated with the VSGB. The stories presented in this essay briefly explore the critical reading of text which I argue is central to creating more gender-inclusive ECE spaces; these books have the potential to inspire much-needed critical considerations with young children in early learning settings. Through this approach to shared book readings (Anderson et al., 2004), storytime is remade into an affirming activity for children of all genders.

While not exhaustive, this essay's selection of picture books provides examples of children's literature that challenge Western ideals of binary sex-gender performativity in early childhood. The picture books featured in this essay were selected through a process of elimination, based on criteria I determined prior to the physical and online searches conducted within university and public library collections of children's literature. Each text explores the intersection between the socializing context of Western schooling and children's gender identity development. In other words, only picture books that reveal the protagonists' formal schooling environments to be powerful socializing contexts for their gender performance are discussed here. My analysis of the following three books is meant to provide an entry into developing a critical reading practice between educators and students so as to better support gender diversity within early learning environments. Relying on the accessible language and narrative structure of picture books will help teachers guide storytime in productively disruptive ways during storytime through a critique of the sociocultural construction of gender.

The centering of a protagonist who remains true to their gender identity for the duration of the story is the other methodological criterion for the inclusion of the following picture books into my analysis. Put another way, the main characters in these texts do not temporarily transgress the gendered social boundaries associated with their SAAB only to "return" to normative gender performance at the end of the story (Friddle, 2017). This methodological requirement significantly narrowed down potential texts from which to build my inquiry, as it is common for female protagonists in children's literature to "begin as tomboys, morphing into proper young ladies late in the text" (Friddle, 2017, p. 118). Within the picture book genre, gender nonconformity is frequently and problematically portrayed as a fleeting or short-lived excursion into misbehaviour for cisgender characters. Furthermore, the majority of children's books featuring transgender characters rely on a troublesome trope of "emphasized femininity" (Blaise, 2005, p. 21), with "little recognition by the trans female characters ... that there are numerous ways to identify, perform identity, and exist as a female" (Crawley, 2017, p. 32). While the main character of I Am Jazz often expresses herself in this characteristically "feminine" way, this portrayal does not make this expressivity somehow less authentic or valid than other ways of expressing one's female gender identity, whatever that looks like. What's more, this particular text remains an important contribution to any picture book library, being one of the few illustrated stories for young readers featuring a transgender protagonist of celebrity (and therefore role model) pop culture status. Representations of transgender and intersex characters in children's literature unfortunately remain peripheral. In these respects, the picture book genre has much farther to go in representing gender diversity. What's more, Ann Travers (2018) writes, "the circumstances under which children experience gender-both the gender that is imposed on them and the gender they feel themselves to be-are complex and difficult to unpack" (p. 16). As a cisgender educator and caregiver, this caveat is a necessary consideration for contextualizing my analysis.

\section{Gender as symbolic in Jacob's New Dress}

Gendered markers are visually symbolic objects, clothing, and valences that discursively carry gendered meanings within and through their presence on children's bodies. The symbolic significance of these markers is socioculturally derived, with these "objects" often representing an extension-and key part-of gender performance. However, it cannot be overstated that, under this definition, body parts are not gendered markers but sex characteristics. 
In this way, my application of "gender as marked” builds on Butler's (1990) theorization of it (p. 16) to suggest that one of the ways in which childhood gender is made visible is through clothing and costuming. Children's gender expression is made recognizable through, and is partially defined by, the presence of certain (non)gendered markers on or near their bodies. In Western contexts, dresses are an example of a gendered marker with a long history of feminine association. In response to this gender marking, Jacob's New Dress, written by Sarah and Ian Hoffman and illustrated by Chris Case, tells the story of a child assigned male at birth who loves to wear dresses.

This book contains what Katie Sciurba (2017) refers to as a "discernible pattern" whereby "the [story] revolves around a 'problem' associated with the young male protagonist's gender variance" (p. 281). As represented in the selected image, Jacob, during a show-and-tell activity at school, proudly displays a dress he made with his mother while his peers speculate about his gender-nonconforming expression. The familiarity of "circle time" (Hoffman \& Hoffman, 2014, p. 25) is narratively juxtaposed with the disruption to gender norms that Jacob's dress represents; his chosen gendered marker challenges the ways in which the VSGB tends to be surreptitiously reproduced in early learning spaces. Although he is confident in his dress, the personal validation he experiences from sharing it with the class is diverted by an outspoken classmate's refusal to accept Jacob's gender expression as legitimate. Through this public display of denial, Christopher discriminately renders (or tries to render) Jacob unrecognizable because of his gender nonconformity. Jacob is discursively placed under the scrutiny of the VSGB and is faced with the realization that his gender expression conflicts with the "masculine" expectations associated with his sex. As a coping strategy, Jacob dissociates from the classroom setting: "He could hear Ms. Wilson and the other kids talking, but their words sounded far away" (Hoffman \& Hoffman, 2014, p. 26). This is not a gender-affirming classroom moment. And-while I appreciate the teacher's linguistic manoeuvre in response to Christopher's first question (Ms. Wilson shifted the attention away from Jacob to a wider sociocultural, gendered phenomenon) - a critical reading of this text during storytime demands more of all educators and children within the ECE context. Recognition of gender identity is at once an individual and group sociocultural responsibility. This recognition is a basic human right that all involved in the learning process must respect and uphold in order to make ECE spaces inclusive and empowering (Bill C-16, Parliament of Canada, 2017).

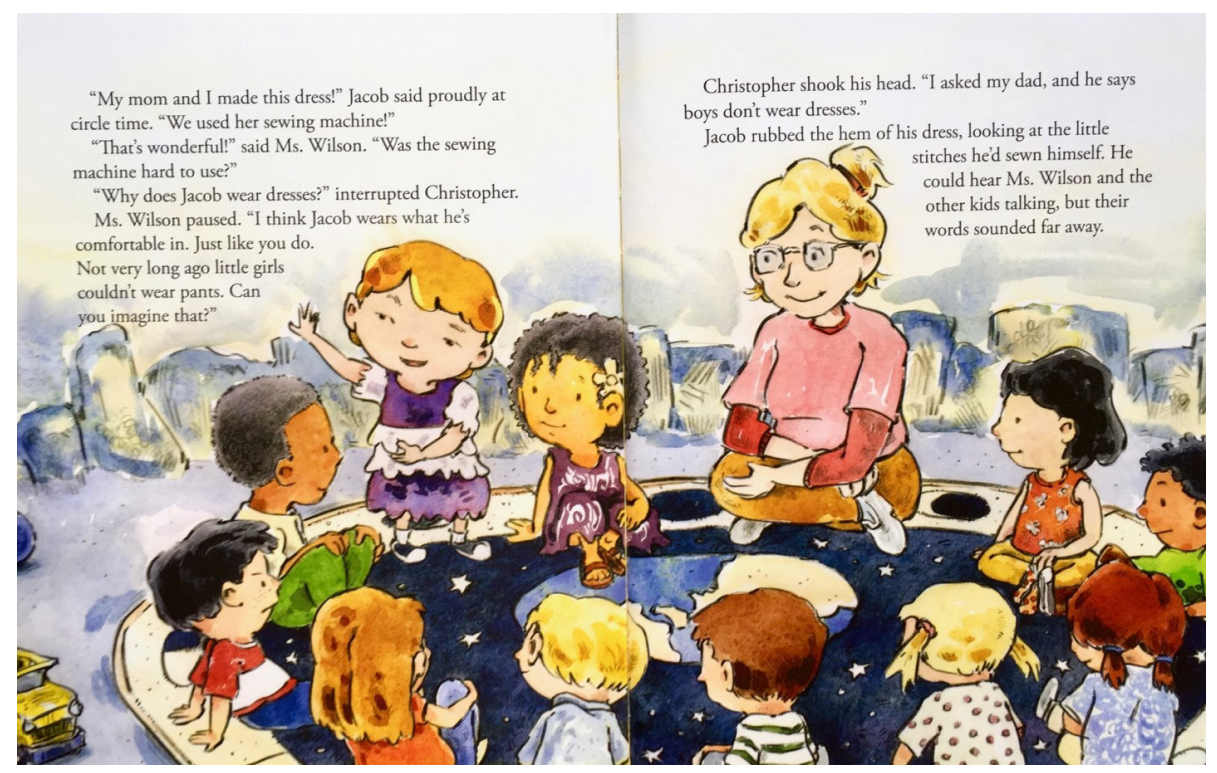

Figure 1. Jacob shows off his new dress at school, demonstrating self-advocacy (Crawley, 2017) and pride in his gender-nonconforming expression (Hoffman \& Hoffman, 2014, pp. 25-26). 
This picture book excerpt shows the social mechanism behind what Jennifer Earles (2017) refers to as "presenting the disruption of normative gender as a process characters must endure to overcome diversity," which Earles believes "subsequently ask[s] children to identify some as normal and others as not" (p. 370). Due to their positions of authority, educators have a special responsibility to step in and stand up for marginalized children before those children dissociate from the sociocultural context of the classroom. Tsao (2008) writes that "gender identity is a pervasive social classification that is established early in childhood and is an important aspect of self-esteem" (p. 109); therefore, teachers must field children's curiosities about gender nonconformity with conscientiousness and compassion. This is where strong boundaries in response to intolerant comments from cisgender children who (un) intentionally perpetuate discriminatory gender-based ideologies is required of educators. An example of a more inclusive response to Christopher's insistence that "my dad ... says boys don't wear dresses" (Hoffman \& Hoffman, 2014, p. 26) is something like, "It's good you're asking questions, Christopher, but let's remember to be respectful towards the differences between all of us. There are many ways to be. Anyone can wear a dress in my classroom if it makes them feel good. If you or your dad want to talk about this, maybe the three of us can discuss it after school." At the same time this kind of response avoids antagonizing a parent (Christopher's father), it also makes clear that teachers like Ms. Wilson are actively shaping their classrooms to be welcoming and affirming-rather than restricting - spaces for diverse gender expressions and identities. Feedback along these lines works to validate both Christopher's and Jacob's experiences by acknowledging and building off of the understandings about gender that each child brings to the classroom. Because why is it only up to Jacob to do the work of disrupting gender in the classroom?

Crawley (2018) discusses the ways in which self-advocacy plays an important role in the lives of many gendernonconforming children (p. 35). Additionally, Sciurba (2017) critiques similar storylines to Jacob's New Dress as too reliant on a particular narrative framing: "Although these characters' families and/or peers do not (fully) embrace them," Sciurba writes, “... the protagonists all achieve much-needed self-acceptance and end their stories valorized” (p. 289). Although the lesson in Jacob's New Dress is one of self-acceptance and authentic gender expression, Jacob is also positioned as nonnormative in ways that isolate him from other children, especially the boys, in his class. Jacob's disruption of gender norms is presented as a social obstacle that he semi-successfully overcomes as a result of self-advocacy. However, gender-nonconforming children like Jacob would not be required to validate their gender expression to others, Sciurba asserts, "if society did not so strictly adhere to assumptions about what boys and girls are and what they can/should do" (p. 291). When exploring this book with young learners, educators can initiate conversations about the myriad ways that everyone's-adult and children's-gender identities are expressed differently in different situations. Too, discussions about the ways in which cisgender children can be allies to their gender-nonconforming peers can be inspired by this book. For example, Jacob and Christopher express their gender identities differently-but what did readers witness these two characters having in common? What could Christopher have done to show friendship and acceptance towards Jacob? For children, whose social networks widen once they begin formal schooling, the external validation tied to "having others acknowledge and support" (Crawley, 2018, p. 35) one's gender identity and expression at a young age is very important. Storytime discussions about this book can explore what makes children feel safe, accepted, and loved for who they are by the people in their lives, an activity prompt that will perhaps lead to craft opportunities.

This text teaches children about the sociocultural (and restrictive) meanings attached to certain gendered markers, such as dresses, in Western contexts. Jacob's New Dress offers opportunities for discussions about how kindness towards others is a social skill that children of all genders can develop and practice in peer relationships. In these ways, Jacob's New Dress is inclusive in its message about childhood gender nonconformity. 


\section{"Why do I have to be just one thing?": Breaking beyond the binary}

From the Stars in the Sky to the Fish in the Sea, written by Kai Cheng Thom and illustrated by Wai-Yant Li and Kai Yun Ching, stands out for being one of the only picture books currently published that uses they/them pronouns. In this story, the protagonist, Miu Lan, is born "when the moon and the sun were in the sky, so the baby couldn't decide what to be" (Thom et al., 2018, p. 4). This is why the pronouns they/them are more representative of Miu Lan as a nonbinary character. This framing of Miu Lan's birth represents the fluidity of expression and complexity of identity that exist beyond the dualism of the VSGB. When Miu Lan asks, "why do i have to be just one thing?" (Thom et al., 2018, p. 29), the VSGB is directly challenged. This child refuses to be categorized based on a dichotomous positioning of gender because it does not accurately capture how they know themself as gendered being. Thom et al. (2018) are intentional about using gender-neutral markers, such as shells and feathers (p. 24), as part of Miu Lan's gender expression, situating Miu Lan's performativity as beyond the binary of traditional notions of masculinity and femininity.

Put another way, Miu Lan's clothing choices in these illustrations are symbolic of their gender nonbinary expression. Miu Lan sports red Mary Janes (traditionally worn by female bodies) with a baseball cap over closely cropped hair (discursively marked as male). The stylistic combination of these gendered markers offers a visual disruption to Western binary gendered expectations, especially in comparison to the gender-normative clothing worn by the other children in these illustrations. Strategically positioned on the opposite page from (perhaps in opposition to) Miu Lan, there exists a marked gendered division between the characters' performativity, with many of the other children presenting according to the VSGB (such that long hair is paired with skirts or the colour pink, for instance). Thus, based on Miu Lan's nonconforming gender markers, and in contrast to their peers' expression, they are made unrecognizable through the lens of the VSGB.

"boys don't play hopscotch!" said a little girl.

"are you a boy or a sirl, anyway?" asked a little boy. "didn't you have a shell the other day?" asked a little girl. "and feathers the day before?"

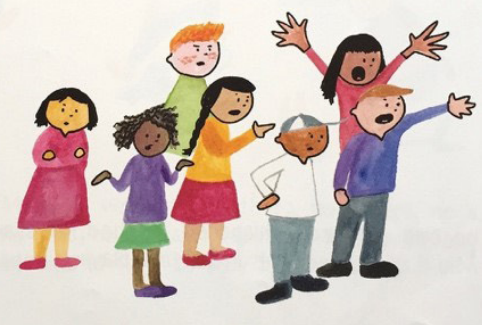

"what are You supposed to BE?"

said several children at once

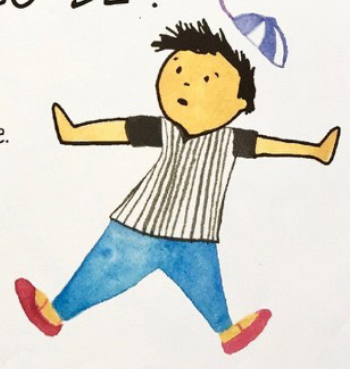

Figure 2. At school, Miu Lan's peers treat Miu Lan unkindly, as a response to their own inability to recognize Miu Lan's gender according to the VSGB (Thom et al., 2018, pp. 24-25).

As much as Miu Lan's story is about self-acceptance and expression, this text also demonstrates the ways in which peer socialization influences children's gender development (Reich \& Vandell, 2011). Schools as sites of gender socialization, particularly through the inclusionary and exclusionary politics of the playground, are explored in this children's book, tracing the social ups and downs experienced by a young nonbinary protagonist who possesses visible differences in childhood gender expression from their peers. While their gender identity and expression are ultimately configured as a gift, Miu Lan still experiences mistreatment and rejection from their 
peers, a school-based experience that is far from fictional for many gender-nonconforming, nonbinary, gendercreative, and transgender children (Meyer \& Leonardi, 2018). On these picture book pages, Miu Lan is rendered unrecognizable by their schoolyard peers on account of their gender-nonconforming performance. Because Miu Lan identifies and expresses themself as nonbinary-meaning that they do not conform to "either" male or female gender designation and/or presentation-their peers demand Miu Lan to explain themself in order to become recognizable: "what are YOU supposed to BE?" (Thom et al., 2018, p. 25). Certainly, this is a very rude question to ask someone of any age and gender presentation. However, this text-based moment reveals children's complicity in maintaining the VSGB through the social policing of gender nonconformity among their peers. Due to the pervasiveness of the male/female binary in Western culture, Miu Lan's peers are unable to recognize Miu Lan's gender performance, pressing Miu Lan to categorize themself into one of two gendered options: "are you a boy or a girl, anyway?" (Thom et al., 2018, p. 24).

For Miu Lan, this question is impossible to answer; this binary does not fit the ways in which they know themself as a gendered being. They like playing hopscotch but they aren't a girl; they wear feathers sometimes but they're a human child, not a bird. Sara Ahmed's (2000) theorization about the ways in which strangers are socioculturally interpolated through unfamiliarity and otherness applies to Miu Lan's dilemma, particularly as they struggle to meet their peers' gendered expectations for them: "The knowing of strangers is, in this way, linked to the production of hybridity" (Ahmed, p. 52). This definition of hybridity applies to the in-between space wherein Miu Lan resides as a child encountering external gender expectations; Miu Lan's gender identity is much more fluid than binary social classifications such as male/female or masculine/feminine. As a protagonist who moves between Victorian distinctions of "boy" and "girl," Miu Lan embodies a powerful sense of gender hybridity-whether or not this nonbinary expression is fully understood by, or recognizable to, others.

Yet Thom et al. (2018) spin the narrative so that this character's perceived unrecognizability is not something that ought to be feared or made "strange" (Ahmed, 2000, p. 50) by young readers but admired instead. Miu Lan's special skills (they can fly) and gender-creative expression end up being the very qualities that transform Miu Lan's peer relationships, especially when their classmates realize they unfairly and solely judged Miu Lan as a potential playmate based on their gender nonconformity. By sharing From the Stars in the Sky as a storytime text, gender-nonconforming children will be able, as Sciurba (2017) writes, "to see themselves in stories with or without happily-ever-after resolutions, but in stories that prove their lives are important" (p. 291).

This picture book communicates that support and understanding for gender nonconformity is both deserved and imaginable from their social communities. Moreover, Miu Lan's story offers entry points into conversations about the bystander effect (Plötner et al., 2015) as well as activities that encourage children to artistically identify their own special gifts. Engaging children with this text during storytime disrupts the assumption that gender operates according to a binary while also showcasing the role that the school context plays in promoting childhood gender equity.

\section{Knowing one's gendered self: A picture book coming-out story}

With words by Jessica Herthel and Jazz Jennings and illustrations by Shelagh McNicholas, I Am Jazz tells the true story of a transgender female child, Jazz Jennings. Jazz describes her childhood transgender identity as having "a girl brain but a boy body" (p. 8). Because of her SAAB, Jazz's parents and teachers expect her to perform gender in traditionally masculine ways: "They'd always thought of me as a boy" (p. 11). However, this ascription of the VSGB onto Jazz's body does not represent her felt sense of gender (Stachowiack, 2017). As Dana Stachowiack (2017) discusses, "the social construction of our gender and felt sense are not the one and the same, but are connected 
and also in tension" (p. 536). Jazz, as a trans child, both challenges the VSGB through asserting her gender identity as female while also manipulating this hegemony as a means of defining the direction of her transition. This text tells the story of how Jazz makes the internal understanding of herself outwardly recognizable to others through the expressed embodiment of "emphasized femininity" (Blaise, 2005, p. 21). As part of her social transition, Jazz explains how wearing "girl clothes at school" and changing her name "felt much more like being ME" (Herthel et al., 2014, p. 17). For Jazz, the previous incongruity she experienced between her gender identity (her brain) and the gender expression assumed by her SAAB (her body) is addressed through her feminine performativity. In this, Jazz's narrative teaches young readers about the sociocultural construction of gender by making visible the moments in which her gender identity is often stifled as a result of biological assumptions other people make about her gender performance.
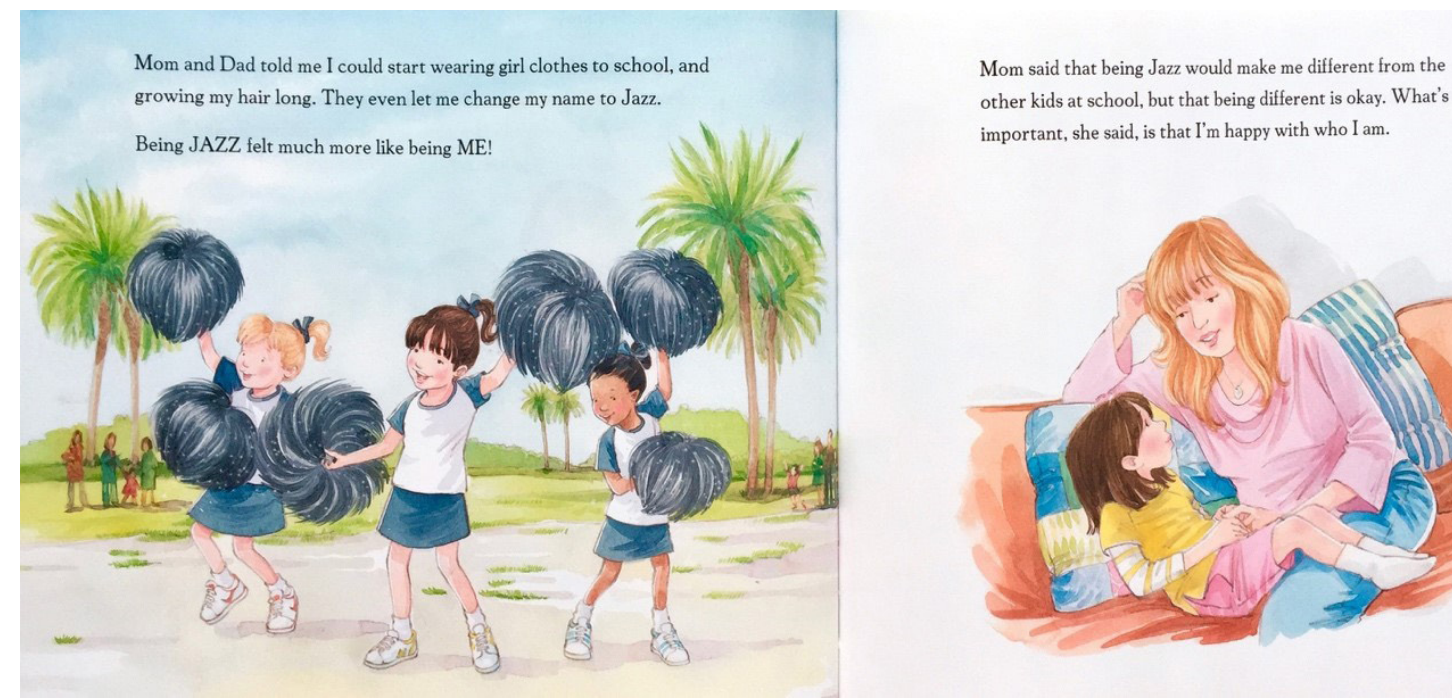

Mom said that being Jazz would make me different from the other kids at school, but that being different is okay. What's important, she said, is that I'm happy with who I am.

Figure 3. Jazz, a transgender child in the book I Am Jazz (2014), expresses her gender identity through "wearing girl clothes at school" (Herthel et al., pp. 17-18) following her social transition.

According to Travers (2018), 'the relationship between 'transgender' and 'childhood' is a troubled one given that children are not typically credited with the ability to authenticate their own gender identities or to know themselves" (p. 41). Jazz's story reminds readers that children are not born as gendered beings; gender develops in early childhood. Gendered meanings are attached to particular children's bodies and, in Western culture, children are socialized to perform gender according to a binary that, in part, presupposes male body parts to indicate exclusive masculine performance. Jazz continually confronts this assumption prior to, during, and after her social transition. This is portrayed through the image of Jazz and her mother discussing the potential misunderstandings Jazz may experience at school after coming out as transgender (Herthel et al., 2014, p. 18) - a sociocultural process that directly confronts the VSGB as an organizational and categorical discourse within early childhood and elementary school spaces. This illustration is accompanied by another that shows Jazz thriving and smiling during extracurricular activities as a result of finally being able to express her authentic gender identity at school. This contrast is indicative of transformation and presents an empowering message to young readers. Through the intimate awareness of her self as a gendered being-even in early childhood_Jazz proves herself to be a child capable of self-promotion (Crawley, 2017; Friddle, 2017; Sciurba, 2017) through her resistance of sociocultural norms limiting her self-expression: "Pretending I was a boy felt like a lie" (Herthel et al., 2014, p. 14).This speaks to the role of the adults in transgender children's lives. When it comes to transgender children's social transitions, Meyer and Leonardi (2018) write, "it's crucial to follow their lead, not encouraging social or public transitions 
unless/if they are ready/desire to come out" (p. 460). As Jazz's story shows, we must listen to, learn from, and believe children when they speak up about their gender identities. Sullivan and Urraro (2019) assert that "understanding and advocating for this vulnerable population is a critical role of early childhood educators" (p. 5), particularly if trans children do not have supportive guardians at home. One of the most important takeaways from $I$ Am $J a z z$ is that no one knows Jazz as well, or as intimately, as she does. Yet this picture book contains only one child's coming out story. Many transgender children's social transitions look very different from Jazz's. In fact, Meyer and Leonardi write, "there is much diversity within individuals who identify as trans" (p. 460). Stories like Jazz's help readers to learn from the lived experiences of trans people, but Filipović (2018) asserts that educators and other adults must remain "aware of gender representation issues and critically reflect on the content of children's books and the messages they are conveying" (p. 311). For instance, Crawley (2017) points out that "currently available representations of trans individuals within picture books are predominantly female" (p. 32). Teachers can reflect on which sociocultural factors are limiting diverse representations of transgender characters in picture books by asking: What is significant about transgender representation in children's literature in this moment in history? Whose stories are being shared and whose are missing?

This story is affirming of transgender children's identities through Jazz's self-representative steadfastness as well as the acceptance and support she receives from her community. Nevertheless, when sharing stories like I Am Jazz in ECE spaces, special attention must be taken to avoid placing "the focus of the problem on the transgender body" (Meyer \& Leonardi, 2018, p. 454), instead situating instances of gender disruption as occurring within "schools embedded in a culture of cisnormativity" (p. 454). Western early learning settings are situated within overlapping social systems of stratification that shape children's and educators' lived experiences in complex, nuanced, and individuated ways. Cisnormativity, the hegemonic supposition emboldened by the VSGB (that all children identify with the gender associated with their SAAB) - is one of these systems. The circulation of cisnormativity is something that educators must take into consideration when reading books like I Am Jazz during storytime, addressing head-on any instances of dead-naming (i.e., referring to a trans or nonbinary person with a name they no longer use) or other bullying behaviour. Meyer and Leonardi advocate for "early changes and efforts to promote respect and affirming for gender diversity and students' identities writ large" (p. 460), and a critical reading of this book during storytime would be one way to implement such efforts.

\section{Limitations, considerations, and directions for future research}

The main limitation of this essay is that, at the time of publication, these texts have yet to be "tested" in an early learning setting. What's more, integrating these picture books into ECE learning contexts where policies around nondiscrimination of sexual orientation and gender identity-such as SOGI 123 in British Columbia (The ARC Foundation, 2020) - are not fully drafted, supported, or implemented may prove challenging. As Meyer and Leonardi (2018) remind us, "the space that is created when people engage in these conversations is not an easy one, oftentimes making it difficult to navigate participation" (p. 457). Yet, in responding to the Canadian Human Rights Act (2017), it is crucial that these books to be incorporated into ECE curriculum as part of antisexist and antidiscrimination efforts. Picture books provide conversational starting places; children can take the lead in discussions about gender-nonconforming texts, and educators can rely on students' visceral reactions and comments to guide critical readings of picture books during storytime. This pedagogical approach requires a willingness on the part of educators to discuss, support, and defend the sociocultural construction of gender with children as an individual's performance (Butler, 1990) of their gendered self. By responding openly and honestly to children's curiosities - while simultaneously encouraging attitudes of empathy, inclusion, and respect-educators can better support and discuss the validity and diversity of gender nonconformity with young students. More picture books about the diversity of childhood gender nonconformity must continue to be shared, written, and 
illustrated for young audiences, in order to promote empowerment in ECE spaces.

A gender critical reading practice has the potential to increase representation of gender diversity in ECE even as these texts "function in limited vehicles for a socially-just education" (Sciurba, 2017, p. 281). The messages in picture books can be powerful and lead to transformative thinking, but these texts only come alive as catalysts for social change when accompanied by critical discussions about gender. Future research could examine other ways in which ECE settings are challenging the VSGB either through play-based learning interventions, curriculum design, or teachers' commitment to inclusive-language choices, as well as the tendency of sex-segregated activities to continue to shape classroom activities.

\section{Conclusion: Making ECE more inclusive by disrupting gender during storytime}

Storytime is laden with sociocultural messages for children about "acceptable" ways of being gendered. Yet disrupting gender through literacy practices is one way to "celebrate" queer texts (Earles, 2017, p. 372). To disrupt gender during storytime, Earles (2017) asserts, educators must "consider, as a central aspect of critical or feminist pedagogy, how to expand children's narrative resources of race ... and gender through the ... promotion of desirable disruptive texts" (p. 439). While conformity to the VSGB is indeed one way to be and move through the world, it is certainly not the only, nor the most valid, way to perform one's gender identity in early childhood. Although children's literature in many ways has evolved beyond stereotypical gender roles to offer more diversity and equity (Mattix \& Sobolak, 2014), a collaborative, critical reading of picture books in ECE will lead to a more empowering, accepting community of practice. Through educator awareness of the ways in which children learn about, internalize, and are socialized to perform gender, analytical literacy skills can be taught in early childhood through a mutually beneficial and dialogical learning process. Gender literacy through picture books therefore empowers children to learn important social skills such as self-confidence, self-advocacy, and empathy towards difference.

The books presented in this essay resist the VSGB to varying degrees, but taken together, this collection makes a valuable addition to any early learning library. By sharing picture books such as Jacob's New Dress, From the Stars in the Sky to the Fish in the Sea, and I Am Jazz in ECE, more inclusive spaces are created for children of all genders. These books are important to feature in ECE because when children are recognized for who they are as gendered beings, they also become better learners and community members, eager to share their thoughts, feelings, and ideas with their peers and teachers. A critical disruption of gender during storytime is therefore a necessary, identity-affirming activity that recognizes and honours the braveness, breadth, and beauty within the spectrum of childhood gender diversity. 


\section{References}

Ahmed, S. (2000). Who knows? Knowing strangers and strangerness. Australian Feminist Studies, 15(31), 49-68. https://doi. org/10.1080/713611918

Anderson, J., Anderson, A., Lynch, J., \& Shapiro, J. (2004). Examining the effects of gender and genre on interactions in shared book reading. Reading Research and Instruction, 43(4), 1-20. https://doi.org/10.1080/19388070409558414

Blaise, M. (2005). Playing it straight!: Uncovering gender discourses in the early childhood classroom. Routledge.

Boler, M. (1999). A pedagogy of discomfort: Witnessing and the politics of anger and fear. In Feeling power: Emotions and education (pp. 175-203). Routledge.

Butler, J. (1990). Gender trouble. Routledge.

Butler, J. (2003). Violence, mourning, politics. Gender and Sexuality, 4(1), 9-37. https://doi.org/10.1080/15240650409349213

Butler, J. (2004). Longing for recognition. In Undoing gender (pp. 131-151). Routledge.

Colliver, Y. (2017). From listening to understanding: Interpreting young children's perspectives. European Early Childhood Education Research Journal, 25(6), 854-865. https://doi.org/10.1080/1350293X.2017.1380882

Crawley, S. A. (2017). Be who you are: Exploring representations of transgender children in picturebooks. Journal of Children's Literature, 43(2). https://www.childrensliteratureassembly.org/uploads/1/1/8/6/118631535/be who you are 1.pdf

Crisp, T., \& Hiller, B. (2011). "Is this a boy or a girl?": Rethinking sex-role representation in Caldecott Medal-winning picturebooks, 1938-2011. Children's Literature in Education, 42, 196-212. https://doi.org/10.1007/s10583-011-9128-1

Earles, J. (2017). Reading gender: A feminist, queer approach to children's literature and children's discursive agency. Gender and Education, 29(3), 369-388. https://doi.org/10.1080/09540253.2016.1156062

Filipović, K. (2018). Gender representation in children's books: Case of an early childhood setting. Journal of Research in Childhood Education, 32(3), 310-325. https://doi.org/10.1080/02568543.2018.1464086

Friddle, M. E. (2017). Who is a "girl"? The tomboy, the lesbian, and the transgender child. In T. Clasen \& H. Hassel (Eds.), Gender(ed) identities: Critical rereadings of gender in children's and young adult literature (pp. 117-133). Routledge.

Golden, J. C., \& Jacoby, J. W. (2018). Playing princess: Preschool girls' interpretations of gender stereotypes in Disney princess media. Sex Roles, 79(5), 299-313. https://doi.org/10.1007/s11199-017-0773-8

Gritter, K., Vriend Van Duinen, D., Montgomery, K., Blowers, D., \& Bishop, D. (2017). Boy troubles? Male literacy depictions in children's choices picture books. The Reading Teacher, 70(5), 571-581. https://doi.org/10.1002/trtr.1559

Herthel, J., Jennings, J., \& McNicholas, S. (2014). I am Jazz. Dial Books for Young Readers (Penguin Group).

Hoffman, S., \& Hoffman, I. (2014). Jacob’s new dress. Albert Whitman \& Company.

Keenan, H. B. (2017). Unscripting curriculum: Towards a critical trans pedagogy. Harvard Educational Review, 87(4), 538-556. https:// doi.org/10.17763/1943-5045-87.4.538

Kim, S. J. (2016). "Pink is a girl's colour": A case study of bilingual kindergarteners' discussions about gender roles. Critical Inquiry in Language Studies, 13(4), 237-260. https://doi.org/10.1080/15427587.2016.1163494

Mattix, A., \& Sobolak, M. J. (2014). Focus on elementary: The gender journey in picturebooks: A look back to move forward. Childhood Education, 90(3), 229-233. https://doi.org/10.1080/00094056.2014.912061

McClung, N. A. (2017). Learning to queer text: Epiphanies from a family critical literacy practice. The Reading Teacher, 71(4), 401-410. https://doi.org/10.1002/trtr.1640

Meller, W. B., Richardson, D., \& Hatch, J. A. (2009). Using read-alouds with critical literacy literature in K-3 classrooms. Young Children, 
64(6), 76-78. https://www.jstor.org/stable/42731056

Meyer, E. J., \& Leonardi, B. (2018). Teachers' professional learning to affirm transgender, non-binary, and gender-creative youth: Experiences and recommendations from the field. Sex Education, 18(4), 449-463. https://doi.org/10.1080/14681811.2017.1411 $\underline{254}$

Parliament of Canada. (2017, July 19). Bill C-16: An act to amend the Canadian Human Rights Act and the Criminal Code, Chapter 13. Statutes of Canada. https://www.parl.ca/Content/Bills/421/Government/C-16/C-16 4/C-16 4.PDF

Plötner, M., Over, H., Carpenter, M., \& Tomasello, M. (2015). Young children show the bystander effect in helping situations. Psychological Science, 26(4), 499-506. https://doi.org/10.1177/0956797615569579

Reich, S. M., \& Vandell, D. L. (2011). The interplay between parents and peers as socializing influences in children's development. In P. K. Smith \& C. H. Hart (Eds.), Blackwell handbook of childhood social development (2nd ed.; pp. 263-280). Blackwell.

Sciurba, K. (2017). Flowers, dancing, dresses, and dolls: Picture book representations of gender-variant males. Children's Literature in Education, 48(3), 276-293. https://doi.org/10.1007/s10583-016-9296-0

Stachowiack, D. M. (2017). Queering it up, strutting our threads, and baring our souls: Genderqueer individuals negotiating social and felt sense of gender. Journal of Gender Studies, 26(5), 532-543. https://doi.org/10.1080/09589236.2016.1150817

Sullivan, A. L., \& Urraro, L. L. (2019). Voices of transgender children in early childhood education: Reflections on resistance and resiliency. Palgrave Macmillan.

The ARC Foundation. (2020). SOGI 123. https://www.sogieducation.org/

Thom, K. C., Ching, K. Y., \& Li, W. (2017). From the stars in the sky to the fish in the sea. Arsenal Pulp Press.

Travers, A. (2018). The trans generation: How trans kids (and their parents) are creating a gender revolution. New York University Press.

Tsao, Y. (2008). Gender issues in young children's literature. Reading Improvement, 45, 108-114. http://citeseerx.ist.psu.edu/viewdoc/ download?doi=10.1.1.691.2538\&rep=rep1\&type $=$ pdf

Yeoman, E. (1999). "How does it get into my imagination?": Elementary school children's intertextual knowledge and gendered storylines. Gender and Education, 11(4), 427-440. https://doi.org/10.1080/09540259920492 